\title{
A evolução do projeto editorial da revista $E m$ Questão
}

\author{
Flavia Ataide Pithan \\ Doutora; Universidade Federal do Rio Grande do Sul, Porto Alegre, RS, Brasil; \\ flavia.pithan@ufrgs.br \\ Adriana Coelho Borges Kowarick \\ Doutora; Universidade Federal do Rio Grande do Sul, Porto Alegre, RS, Brasil; \\ adriana.kowarick@ufrgs.br
}

\begin{abstract}
Resumo: Desenvolveu-se uma pesquisa histórica/descritiva e, posteriormente, interpretativa que analisou a evolução do projeto editorial da revista Em Questão ao longo dos seus 35 anos. Os elementos textuais (títulos, corpo de texto, citações, cabeçalho, rodapés, legendas etc.) e imagéticos (capa, identidade visual, figuras, tabelas, ilustrações etc.) foram primeiramente categorizados, depois comparados e, por fim, analisados, gerando as inferências interpretativas desde a primeira edição da revista até as mais atuais. Verificou-se, entre outros pontos, que o projeto editorial evoluiu adequadamente nesses 35 anos.
\end{abstract}

Palavras-chave: Projeto editorial. Em Questão. Design gráfico.

\section{Introdução}

O artigo apresenta a evolução da revista Em Questão, publicada pelo Programa de Pós-Graduação em Ciência da Informação, da Faculdade de Biblioteconomia e Comunicação da Universidade Federal do Rio Grande do Sul, a partir da apresentação e da análise dos seus projetos editoriais, partindo do primeiro (quando a revista ainda era apenas impressa, até 2003), passando pelo período em que coexistiram as versões impressa e eletrônica (entre 2003 e 2012) e terminando no seu projeto atual (que passou a ser exclusivamente digital, a partir de 2012). O texto propõe um recorte possível para montar uma versão histórica da revista, história essa contada com base nas categorias de design definidas durante a pesquisa.

A revista surgiu em 1986, com o nome de Revista de Biblioteconomia \& Comunicação, como um “[...] periódico criado experimentalmente pelos alunos da disciplina de Projeto Experimental em Jornalismo II, coordenada pelos professores Rosa Nívea Pedroso e Rubens Constantino Volpe Weine" (PASSOS; 
PASSOS; VANS, 2014, p. 9). A proposta era "[...] iniciar o debate sobre as tendências teóricas e práticas da comunicação e divulgar os estudos realizados por professores e alunos da Faculdade de Biblioteconomia" (PEDROSO; WEINE, 1986, p. 2). Mesmo sendo criada especificamente como um projeto de extensão, e por isso não ter assegurada sua periodicidade, a revista teve importante repercussão já em seu lançamento, tanto que a direção da faculdade decidiu tornála uma publicação da Faculdade de Biblioteconomia e Comunicação da Universidade Federal do Rio Grande do Sul (FABICO), desvinculando-a da disciplina que a originou. Entretanto, apesar de seu sucesso inicial, a história da revista é desenhada com grandes mudanças e algumas descontinuidades até 2003, quando passou a ser disponibilizada também por meio eletrônico (EM QUESTÃO, [2020?]).

Além do novo meio de disponibilização, em 2003 a revista passou por outras duas importantes alterações: a troca do nome, de Revista de Biblioteconomia \& Comunicação para Em Questão, e a mudança da periodicidade, que passou a ser semestral. No bojo dessas transformações, estava a vontade de qualificar a revista. Sua entrada no meio digital permitiu o aperfeiçoamento de recursos, a priorização da visibilidade e acesso ágil ao conteúdo da revista (EM QUESTÃO, [2020?]).

Entre 2003 e 2012, a equipe editorial e seus coordenadores trabalharam para o constante aperfeiçoamento da revista, perseguindo os critérios Qualis da CAPES e acompanhando as inovações tecnológicas, no âmbito da produção e da divulgação científica, utilizando o Sistema Eletrônico de Editoração de Revistas (SEER), entre outros movimentos.

A partir de 2012, seguindo a tendência internacional dos periódicos científicos, a Em Questão deixa de ser impressa em papel, passando a ser publicada somente em formato eletrônico. Conforme o coordenador da revista na época, professor Alexandre Rocha da Silva, tal mudança teve como objetivo agilizar a publicação dos conteúdos e otimizar recursos (EM QUESTÃO, [2020?]).

As inovações tecnológicas que deram (e dão) suporte para as transformações, e o aprimoramento no campo da editoração gráfica, igualmente impactaram todas as áreas do conhecimento, impulsionadas principalmente pelo avanço das 
tecnologias digitais. Na área do design gráfico, essa transformação ocorreu graças ao desenvolvimento das chamadas desktop publishing (DTP). Essa prática, de editoração eletrônica das artes-finais de documentos impressos,

[...] foi aparecendo gradualmente nas décadas de 70 e 80, com os primeiros computadores dotados de programas processadores de texto e impressoras de impacto de saída (tipo margarida ou daisywheel), sistemas que começavam a ser utilizados nas universidades e nas grandes empresas para a confecção in house das artes-finais de teses e relatórios de circulação interna ou restrita. Para isso, se usavam inicialmente os computadores mainframes, depois os minicomputadores, e finalmente os PCs. (CAUDURO, 2000, p. 245, grifos do autor).

O caminho aberto por estas novidades tomou direções particulares em cada área e, certamente, envolve algumas questões específicas do design gráfico que estão contempladas neste artigo. Vale citar que as DTPs foram difundidas ao mesmo tempo em que a revista Em Questão foi criada, na segunda metade dos anos 1980. Portanto, são duas histórias bastante contemporâneas e o projeto editorial da revista não poderia fugir da influência dessas tecnologias.

As ferramentas usadas para projeto gráfico e editorial, considerando o último uma especialização do primeiro, em um momento anterior ao surgimento das chamadas desktop publishing, eram deveras rudimentares e limitadas (e talvez até limitadoras), o que tornava o trabalho do diagramador mais difícil e demorado. Havia muita restrição quanto aos projetos, justamente pela falta de recursos. Os softwares mais comumente usados hoje em dia para a editoração eletrônica surgiram na década de 1990. Antes disso, a diagramação das revistas se dava através de processos exclusivamente mecânicos, hoje já em desuso.

O termo desktop publishing vem sendo largamente utilizado nas artes gráficas, como a solução para vários problemas de fluxo de trabalho em diagramação e composição de textos. Traduzindo o termo, que significa editoração eletrônica, apresenta, a cada nova linguagem, aperfeiçoamentos [...]. Na realidade, o desktop publishing nasceu para facilitar a vida de secretárias americanas, que tinham como tarefas postagem de cartas, memorandos com o mesmo conteúdo, porém com dados e endereçamentos diferentes. No início, essa foi a utilização da editoração eletrônica: para entrar nas necessidades das artes gráficas foi um pulo. (COLLARO, 2000, p. 29). 
Um projeto gráfico consiste, basicamente, em uma formação de elementos como cores, tipografia, grid, grafismos em geral, textos, conteúdo e linguagem. Villas-Boas (2003, p. 7) define o design gráfico como uma atividade de "[...] ordenamento estético-formal de elementos textuais e não-textuais que compõem peças gráficas destinadas à reprodução com objetivo expressamente comunicacional". Especificamente o projeto editorial, que se considera uma divisão ou especialização do design gráfico, é a área de atuação do designer responsável por projetar livros, revistas e jornais (O VALOR..., 2004).

A atividade que nasceu com o impresso, amadureceu em paralelo com a evolução dos processos de impressão e foi bastante impactada com o surgimento das tecnologias de editoração eletrônica, agora liberta-se dessa esfera para existir somente no contexto digital. As revistas científicas também acompanharam todos esses movimentos, mas possuem alguns pontos peculiares que serão destacados no artigo.

Como afirmam Oliveira, Santin e Vanz (2015, p. 8), a qualificação dos periódicos científicos "[...] tem sido objeto constante de pesquisa, tendo em vista que o periódico tornou-se o principal veículo de comunicação da ciência". Com isso, acredita-se oportuno e relevante realizar a presente investigação, quando a revista completa seus 35 anos, de forma a contar sua história a partir da evolução do seu projeto editorial, configurando, assim, um novo olhar ainda não explorado.

Nesse sentido, apesar do projeto editorial não compor requisito formal de avaliação de periódicos científicos em nenhum lugar, vai-se além do que propõe Stumpf (2003), que categorizou os parâmetros de avaliação. Julga-se que o projeto editorial também possa ser um fator que colabora para qualificar um periódico científico. Pensamento similar é apresentado por Meadows ${ }^{1}$ (1999 apud PASSOS; PASSOS; VANZ, 2014) e Garret ${ }^{2}$ (2003 apud PASSOS; PASSOS; VANZ, 2014), quando salientam que o design visual vai além do meramente estético, estando relacionado a questões de otimização da comunicação.

A metodologia da pesquisa está descrita na próxima seção deste artigo, seguida pela análise do projeto editorial. Optou-se por expor os conceitos envolvidos em cada parte do artigo na medida que forem aparecendo, assim como 
já foram apresentados alguns ao longo desta introdução. Por fim, são manifestadas as considerações finais da pesquisa.

\section{Metodologia de pesquisa}

A pesquisa constitui-se num estudo exploratório de abordagem qualitativa. Para seu desenvolvimento, num primeiro momento, realizou-se uma revisão bibliográfica a respeito de textos já existentes sobre a Em Questão, artigos que pudessem ter similaridade e/ou que tivessem um viés histórico, alinhados com o que se propõe aqui. Alguns textos encontrados ajudaram a contar a história da revista (GOLIN, 2005; OLIVEIRA; SANTIN; VANZ, 2015; PEDROSO, 2000; PEDROSO; WEINE, 1986) e um deles relata todo um projeto de pesquisa feito em 2012 para aportar o seu novo projeto de identidade visual (PASSOS; PASSOS; VANZ, 2014). Além disso, foram encontrados textos sobre o design de revistas científicas (CASTEDO; GRUSZYNSKI, 2005; CASTEDO; GRUSZYNSKI, 2011).

Num segundo momento, a pesquisa bibliográfica fixou-se nos conceitos do design envolvidos no trabalho e também sobre a evolução das tecnologias digitais aplicadas em design gráfico e editorial. A partir disso, foram definidas quatro categorias para a comparação e quais elementos do design gráfico dentro de cada categoria seriam analisados: (1) diagramação da capa; (2) diagramação do miolo; (3) tipografia e (4) identidade visual.

Na diagramação da capa, considerou-se principalmente a distribuição dos elementos na grade (que é a diagramação propriamente dita). Os elementos apreciados na diagramação foram: a identidade visual; as informações sobre a revista (volume, número, período etc.); as informações textuais sobre os artigos que a revista apresenta; as imagens e as cores. Na diagramação do miolo foram estudadas a grade e a mancha gráfica que mais caracterizam a publicação e também outros elementos que, agrupados, foram rotulados de elementos editoriais (o número da página, o título do artigo na página inicial, o título do artigo nas demais páginas, as informações da revista nas páginas etc.). $\mathrm{Na}$ tipografia, contemplou-se a tipografia da capa (exceto da identidade visual) e do 
miolo, percorrendo as fontes utilizadas nos editoriais e demais páginas da revista e também as fontes aplicadas nas páginas de artigos. Por fim, na identidade visual foram estudados o logotipo, o símbolo e as cores.

Posteriormente, providenciou-se a seleção da amostra a ser estudada. Definiu-se que o ponto de partida seria a primeira edição, de 1986. A partir dessa edição, avançar-se-ia de dez em dez anos nas demais edições, sempre se utilizando a primeira edição de cada um dos anos: 1996, 2006, 2016. A última edição a ser analisada foi definida como a primeira de 2020, tendo em vista que ainda não se avançou uma década inteira. Assim, os cinco anos-base para utilizar como referência na amostra foram: 1986, 1996, 2006, 2016 e 2020.

As imagens componentes do estudo foram retiradas do site da revista (https://seer.ufrgs.br/EmQuestao/index) e também do site do Centro de Documentação e Acervo Digital da Pesquisa da Universidade Federal do Rio Grande do Sul (CEDAP) (https://cedap.ufrgs.br/jspui/), que hospeda as edições de 1986 até 2000. Para a ancoragem da discussão sobre a evolução histórica do projeto editorial, foram criadas imagens em forma de linha do tempo, apresentando os cinco anos-base definidos. Para cada categoria de análise foram elaboradas as linhas do tempo necessárias para representar visualmente a parte da revista observada (amostra) e elucidar as análises e inferências descritas. Foram utilizadas as cores da identidade visual da Em Questão na composição, no intuito de aproximar ainda mais a abordagem da própria revista.

A partir deste desenho de pesquisa, com as quatro categorias de análise definidas, a escolha e o limite da amostra justificado, partiu-se para a análise e interpretação dos dados. A próxima seção trata da explanação do estudo. Retoma e aprofunda as categorias de análise e apresenta, de forma sistematizada, os resultados da interpretação dos materiais estudados e as decorrentes inferências.

\section{Evolução do projeto editorial da revista Em Questão}

No primeiro momento da análise da pesquisa, constatou-se que o projeto editorial da revista era bastante simples no seu surgimento: praticamente sem imagens, impresso em preto e branco, sem muitas variações tipográficas, com identidade 
visual não definida (julgou-se mutável ou indefinida, pois apresentava variações de edição para edição, mesmo que alguns elementos fossem mantidos). $\mathrm{O}$ design seguiu nesses moldes praticamente até 2012, quando a revista deixou de ser impressa.

Para o presente estudo, conforme já indicado, quatro categorias principais foram definidas. Duas delas, diagramação da capa e diagramação do miolo, aportam-se no conceito de diagramação.

O termo diagramação é resultante da palavra diagrama, do latim diagramma, que significa desenho geométrico usado para demonstrar algum problema, resolver alguma questão ou representar graficamente a lei de variação de um fenômeno. (SILVA, 1985, p. 41, grifos do autor).

A decisão de dividir as categorias entre diagramação da capa e diagramação do miolo foi tomada por se acreditar que configuram dois pesos importantes, mas que desde o início do desenvolvimento do projeto editorial de uma revista recebem tratamentos diferenciados por parte do profissional responsável pelo projeto. Além disso, seriam muitas variáveis em uma única categoria, tornando a proposta confusa. Portanto, realizar essa divisão teve o intuito de formular parâmetros de avaliação mais precisos para o contexto do artigo.

Embora o conceito de diagramação, por definição, envolva a escolha e aplicação da tipografia e inclua a distribuição da identidade visual nos projetos, optou-se por separar também estes dois importantes elementos do design em duas novas categorias.

A tipografia foi definida como categoria de análise, pois agrega forte relevância ao projeto editorial da revista, constituída majoritariamente pela linguagem verbal, como muitas das revistas científicas. Esta é uma das peculiaridades dos periódicos científicos, como mencionado na introdução. No seu surgimento, as imagens praticamente não existiam. No volume de 1986, foram encontradas algumas imagens fotográficas apenas no final da revista, na seção Ensaio. No exemplar analisado de 1996, as imagens encontradas foram tabelas, gráficos e esquemas. Algumas imagens encontradas parecem ser fotográficas ou capturas de tela, mas a qualidade do impresso, já digitalizado para 
ser disponibilizado nessa versão, não permite afirmar. De modo diferente, na revista considerada de 2006 foram encontradas imagens fotográficas, gráficos e tabelas, mesmo que ainda em preto e branco, com maior qualidade. Mas dos exemplares que compuseram a amostra, foi somente a partir do ano de 2016 que as imagens ganharam maior espaço, sendo disponibilizadas em cores e com boa qualidade. Ou seja, parece ser a tipografia e suas nuances de diagramação o elemento do design protagonista para a caracterização geral do projeto editorial da Em Questão.

Por fim, a última categoria, identidade visual, foi separada, pois configura, por si só, um dos importantes elementos do design editorial de qualquer revista, seja científica ou não. Segundo a Editora Abril (2000), mesmo que esteja falando sobre revistas comerciais, é a identidade visual da capa da revista que faz o leitor identificá-la. "Quando o leitor olha o logotipo de uma revista, ele a identifica [...]" (EDITORA ABRIL, 2000, p. 136). Os conceitos específicos (logotipo e símbolo) serão tratados mais adiante.

Considerando as quatro categorias definidas para a pesquisa, e já expostas anteriormente, apresenta-se, a seguir, a análise feita da evolução do projeto editorial e as inferências que surgiram ao longo da pesquisa.

\subsection{Diagramação da capa}

A definição de diagramação adotada para a análise equivale à proposta por Neiva (2013, p. 155), sendo a

[...] elaboração de leiaute ou esquema (de dimensões e formatos iguais aos da publicação) em que aparecem devidamente calculados e representados todos os elementos (textos, paginação, legendas, fotos, ilustrações etc.) que compõem o material.

Rabaça e Barbosa (2001) citam que, antes da editoração eletrônica, as etapas percorridas pelo diagramador eram: elaborar rafes (leiautes) para o material; calcular os espaços que as matérias ocupariam; desenhar a grade; realizar as definições tipográficas e, por fim, retrancar os originais. Hoje, todas 
essas etapas são realizadas diretamente no computador através de softwares específicos.

Figura 1 - Diagramação das capas

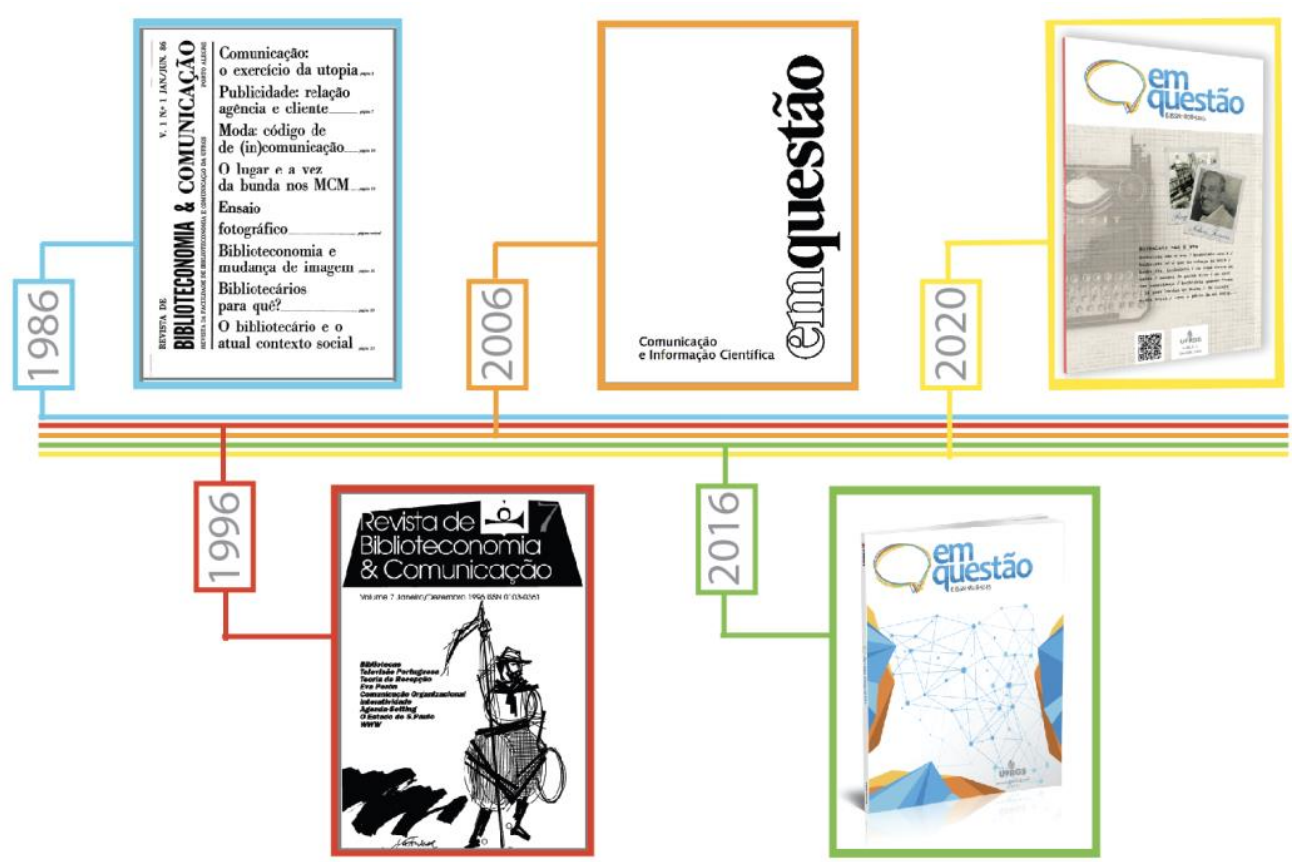

Fonte: elaborada pelas autoras (2021).

A Figura 1 apresenta a linha do tempo com as capas da revista. A capa do primeiro exemplar, também o primeiro item da amostra da pesquisa, é totalmente tipográfica. Em retângulo vertical diagramado à esquerda, com texto deitado (de baixo para cima), aparece a identidade visual juntamente com as demais informações de volume, número, data e local. Os títulos dos artigos aparecem em um segundo retângulo à direita, já com as páginas indicadas, configurando um sumário.

A segunda capa da amostra (Figura 1) traz uma divisão na parte superior com um retângulo horizontal que contém a identidade visual da revista, com as demais informações de volume, número, data e local. Logo abaixo, em outro retângulo, uma ilustração de Joaquim da Fonseca, juntamente com textos que resumem o assunto dos artigos. 
Na terceira imagem da Figura 1, do ano de 2006, já com o nome alterado para Em Questão, a capa apresenta a identidade visual também em retângulo vertical como a primeira, porém diagramado à direita, mas também com texto deitado (de baixo para cima). Fora a identidade visual, apenas aparece a descrição da revista, em texto distribuído horizontalmente em duas linhas e alinhado à esquerda. É interessante ressaltar que foi observado que no site, de 2003 até a primeira edição de 2009, não existe uma capa específica para cada número. O que é apresentado na linha do tempo é o mais próximo do que seria uma capa, e que se conseguiu encontrar no site, na seção Expediente da revista. Portanto, foi considerada como capa a primeira página do expediente.

As duas últimas capas (Figura 1) são de quando a revista entra na era exclusivamente digital. Elas ganham imagens, cores e uma diagramação fixa, que apresenta a identidade visual em um primeiro retângulo horizontal na parte superior (cabeçalho) e reserva um segundo retângulo na parte inferior para as imagens e demais informações (assinatura da UFRGS e atualmente o QR code).

Curioso notar que atualmente a revista está disponível apenas online, mas as capas simulam uma revista impressa, representando inclusive o volume, as sombras e até a lombada do que seria uma revista impressa, através de um mockup em três dimensões. Isso poderia indicar o apego das pessoas ao impresso, ao ponto de algo que só é disponibilizado online remeter ao que seria um exemplar impresso.

\subsection{Diagramação do miolo}

Para analisar a diagramação do miolo da revista, um número maior de elementos entra em cena. Diferentemente das capas, que apresentam poucos elementos, aqui, primeiramente, é necessário empregar o conceito de grade ou grid. Segundo Lupton (2006, p. 113), as grades "dividem o espaço em unidades regulares". Trata-se de uma estrutura modular que define "sistemas para a disposição de conteúdo em páginas, telas ou ambientes construídos” (LUPTON, 2006, p. 113).

Gruszynski e Calza (2013) complementam o conceito evidenciando que uma grade é geralmente dividida por eixos verticais e horizontais (invisíveis), 
dedicada a facilitar o alinhamento de elementos visuais presentes em alguma composição. A partir do formato daquilo que se quer diagramar, são as linhas, as colunas e as margens que organizam o plano onde os elementos do leiaute são distribuídos. A partir da grade é possível dizer quais informações são as principais (as primeiras a serem identificadas) e as secundárias, servindo como um "guia" para o olhar do leitor.

A construção de uma grade está subordinada diretamente ao conteúdo da mensagem e ao formato da publicação e é influenciada pela quantidade de elementos que serão dispostos no leiaute, por isso é possível notar grande variedade quanto ao seu emprego. Ao contrário do que possa parecer num primeiro momento, uma grade confere maior equilíbrio e, ao mesmo tempo, liberdade ao projeto gráfico, garantindo proporções matemáticas entre os elementos.

Para realizar a análise da evolução do projeto editorial na categoria diagramação do miolo, foi necessário elaborar duas imagens de linha do tempo, com dois tipos de materiais retirados da amostra: uma mostrando as páginas editoriais do miolo das revistas e outra mostrando as páginas de artigos.

Figura 2 - Diagramação das páginas editoriais

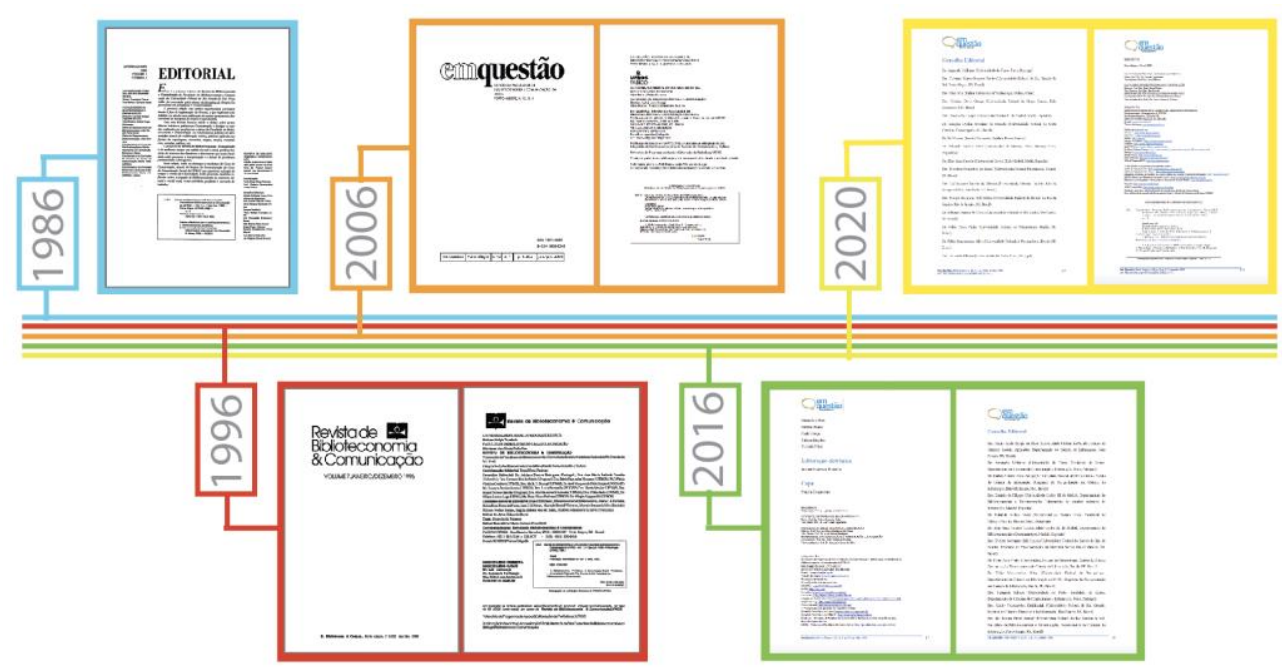

Fonte: elaborada pelas autoras (2021).

Na primeira página interna analisada da revista de 1986 (Figura 2), do editorial, pode-se perceber a diagramação em três colunas, mas gerada a partir de 
uma grade configurada por quatro colunas, agrupada em: $1 \times 2 \times 1$. Todas as demais páginas internas analisadas nessa primeira amostra foram diagramadas em uma única coluna de texto, com predominância do texto alinhado à esquerda ou justificado. A mancha gráfica desses quatro últimos exemplos é bastante monótona, se comparada a do primeiro exemplo, que apresenta até um certo movimento nas distribuições, gerando uma orientação de leitura em diagonal, começando pela esquerda acima e terminando na direita abaixo, equivalente ao estereótipo de leitura ocidental. A partir dessa primeira sequência de páginas internas, não foi possível definir se a mancha gráfica é replicada igualmente em todas as páginas (pares e ímpares) ou se é espelhada.

Figura 3 - Diagramação das páginas internas de artigos

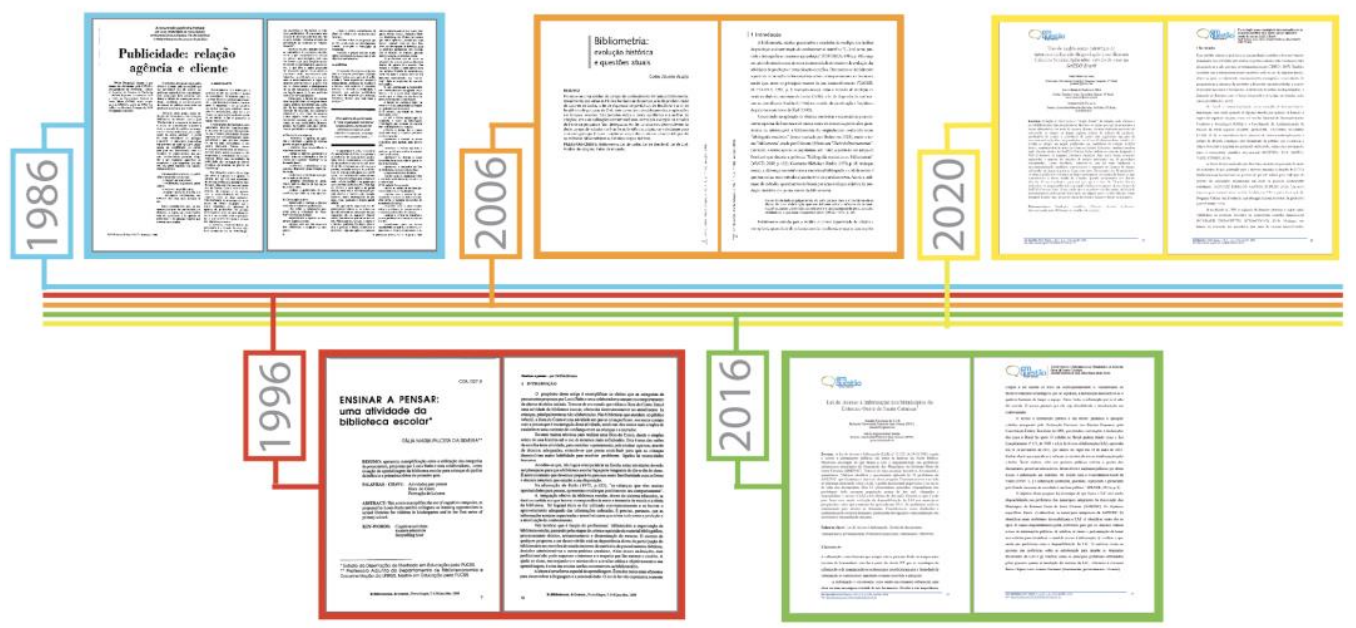

Fonte: elaborada pelas autoras (2021)

$\mathrm{Na}$ segunda sequência de páginas internas analisadas, como mostra a Figura 3, correspondente às páginas de artigos do periódico, pode-se notar uma diagramação diferenciada para a primeira página de cada artigo e as demais páginas do mesmo artigo. Esse recurso é um importante sinalizador para o leitor, que acaba familiarizado com a leitura da revista e entende, quase que inconscientemente, que terminou um texto e está iniciando um outro, agregando ergonomia à tarefa da leitura.

Observa-se, ainda na Figura 3, que os títulos dos artigos vinham mais destacados, com corpo de texto maior, nos três primeiros exemplares analisados. 
Nos dois últimos, ainda existe o destaque, mas é mais discreto do que nos anteriores. Além disso, pode-se verificar que a primeira edição da revista tem uma diagramação em três colunas. Aqui é possível perceber, a partir das informações no rodapé desta edição, que a mancha gráfica é aplicada espelhada. O mesmo ocorre com as edições de 1996 e 2006, porém, nessas duas últimas, a diagramação do texto é feita em uma única coluna. Nas edições de 2016 e 2020, a diagramação também é em uma coluna, mas a mancha gráfica não é espelhada. Em 1986, fios horizontais incrementavam o projeto editorial, o mesmo que faziam fios verticais em 2006, e agregavam hierarquia propondo certa divisão da página.

A partir do novo projeto gráfico da revista (2012), aparece um fio vertical no cabeçalho que separa a identidade visual das informações de identificação do artigo (título e autores) e um fio horizontal que separa o corpo de texto do rodapé, evidenciados nas páginas de 2016 e 2020 (Figura 3). Embora as tecnologias tenham facilitado imensamente a tarefa da diagramação, as páginas internas da Em Questão não parecem mais elaboradas no projeto de 2012 do que as anteriores. Isso talvez se justifique pois para a padronização dos textos - que não contam com profissionais pagos para diagrama-los - foi preciso fornecer um template (PASSOS; PASSOS; VANZ, 2014), onde os próprios autores dos artigos inserem seus trabalhos antes da submissão.

Quando a revista era impressa, não existia a possibilidade de ser publicada sem antes passar pelo trabalho de um profissional, que diagramava suas páginas. Esse procedimento, invariavelmente, agregava profissionalismo ao leiaute. Estando essa tarefa agora ao encargo dos autores dos artigos, entende-se que a simplicidade do projeto seja indispensável, tendo em vista que é utilizado um software editor de texto comum (Microsoft Word) e acessível aos autores, e não um programa paginador profissional como o InDesgin ou o QuarkXPress (ambos da Adobe). Segundo Horie e Pereira (2001), os paginadores pertencem ao grupo de aplicativos que diagrama texto junto com os arquivos vetoriais e bitmaps importados dos outros aplicativos (ilustradores e retocadores), com o objetivo de confeccionar desde livros e revistas até jornais e anúncios publicitários.

\subsection{Tipografia}


Para realizar a análise da tipografia na evolução do projeto editorial da revista é necessário, antes, explorar um pouco mais o tema. "A tipografia é o ofício que dá forma visível e durável - e, portanto, existência independente - à linguagem humana" (BRINGHURST, 2005, p. 17).

Há várias definições de tipografia ao longo da História. Cada uma delas expressa, talvez, um modo de ver o mundo e o papel do designer. Algumas privilegiam as características formais, outras enfocam os aspectos técnicos; outras o seu aspecto utilitário. Tipografia é tudo isso, porém é mais ainda a representação visual da linguagem e, portanto, expressão da cultura. Tipografia compreende o desenho e a produção de letras e a sua adequada distribuição e espacejamento sobre uma superfície (sobretudo o papel e agora o monitor ou tela) para transmitir informação e facilitar a compreensão. (NIEMEYER, 2006, p. 14).

Bringhurst (2005) avalia que o cerne da tipografia é a caligrafia, e como ofício tem preocupações compartilhadas com a escrita e a edição de um lado, e com o design gráfico do outro lado, mas não pertence a nenhum deles. Outro ponto relevante apresentado pelo autor é sobre as poucas alterações ocorridas nos princípios da clareza tipográfica desde a segunda metade do século $\mathrm{XV}$, mesma época quando surgiram os tipos móveis de Gutenberg. Então, mesmo que a computação gráfica tenha capacitado o profissional a produzir e interferir no design das fontes, conforme expõe Rocha (2003), os fundamentos da tipografia mantêm-se inalterados. Isso sugere que em tipografia não há muito mais o que inventar. O que mudou substancialmente foi a forma de desenvolver os leiautes e montar as páginas de texto.

[...] os tipos deixaram de ser, definitivamente, objetos com propriedades físicas; passam a ser sequências digitalizadas em código binário, vistas em tela de computador ou descrições de curvas vetoriais interpretadas por uma impressora. Neste contexto, o repertório da informática também teve que obrigatoriamente ser incorporado pelos designers gráficos para garantir o sucesso no uso ou no desenvolvimento de fontes digitais. (ROCHA, 2003, p. 22).

Vale citar outras importantes contribuições neste domínio: o primeiro Macintosh no início dos anos 1980 com a tela WYSIWYG (what you see is what you get) e o sistema direct-to-plate na segunda metade dos anos 1990, o qual cria 
as matrizes de impressão diretamente a partir do computador, eliminando o fotolito (CAUDURO, 2000).

Para dar conta de apresentar a variedade de tipografias usadas nas edições da revista, foi preciso elaborar quatro linhas de tempo: uma que mostrasse as capas das edições escolhidas como recorte da amostra; uma que mostrasse as tipografias usadas nas páginas editoriais; uma para as primeiras páginas dos artigos; e, por fim, uma linha do tempo com as páginas de artigos que não as iniciais.

Figura 4 - Tipografia da capa

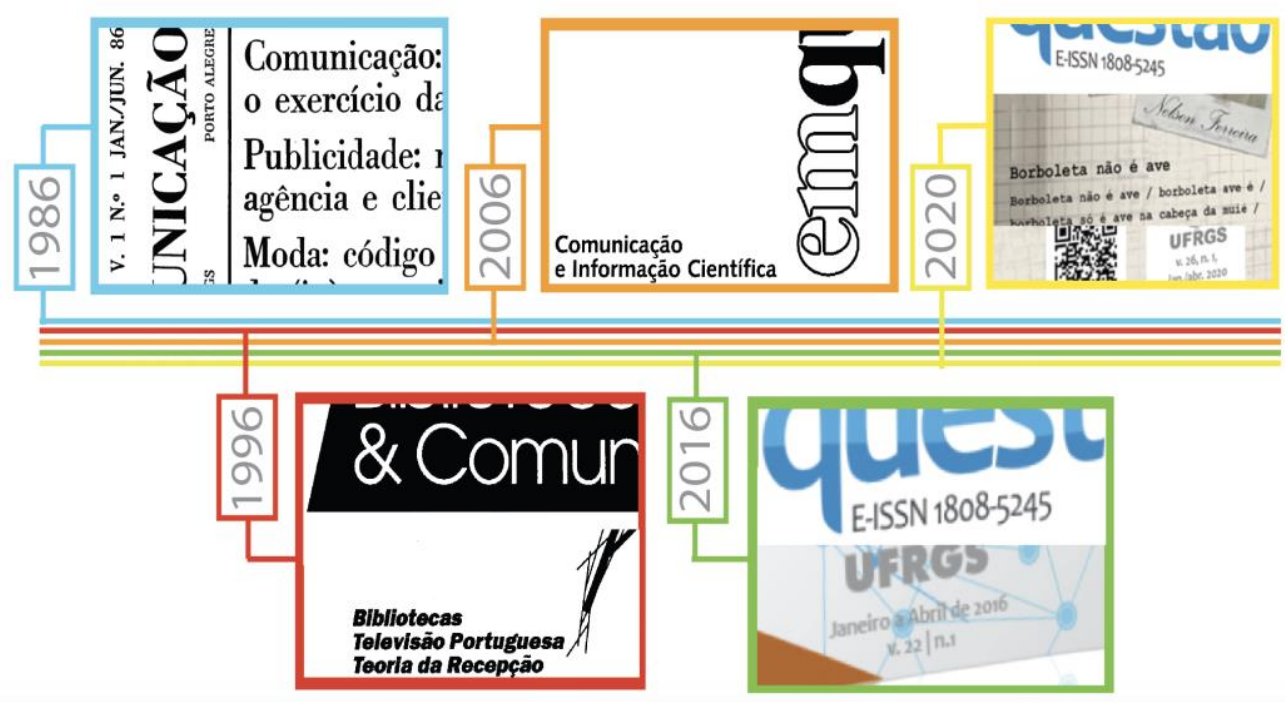

Fonte: elaborada pelas autoras (2021).

A tipografia da primeira capa (Figura 4), de acordo com a classificação proposta por Williams (2005), é moderna. Possui ênfase vertical, transição grosso-fino acentuada e serifas horizontais e finas. A segunda capa possui uma fonte sem serifa, aplicada sem grifos no nome da revista e com itálico nos demais textos. Não apresenta transição grosso-fino e por isso também não há ênfase. A terceira capa mistura um tipo com serifa no nome Em Questão, com um sem serifa na descrição do periódico. As duas últimas capas, que possuem o novo projeto de identidade visual, trazem a tipografia do logotipo (que será tratada adiante), a tipografia da marca promocional da UFRGS - que é a Futura (CAUDURO; FONSECA, 1997) - e nos demais textos são fontes sem serifa, no E-ISSN e nas informações de volume e data. Alguns outros textos aparecem na última capa da 
amostra, mas esses textos são parte das imagens que por vezes ilustram algumas edições, sendo, portanto, variáveis e não elementos fixos da revista e por isso não foram tratados.

Figura 5 - Tipografia das páginas editoriais

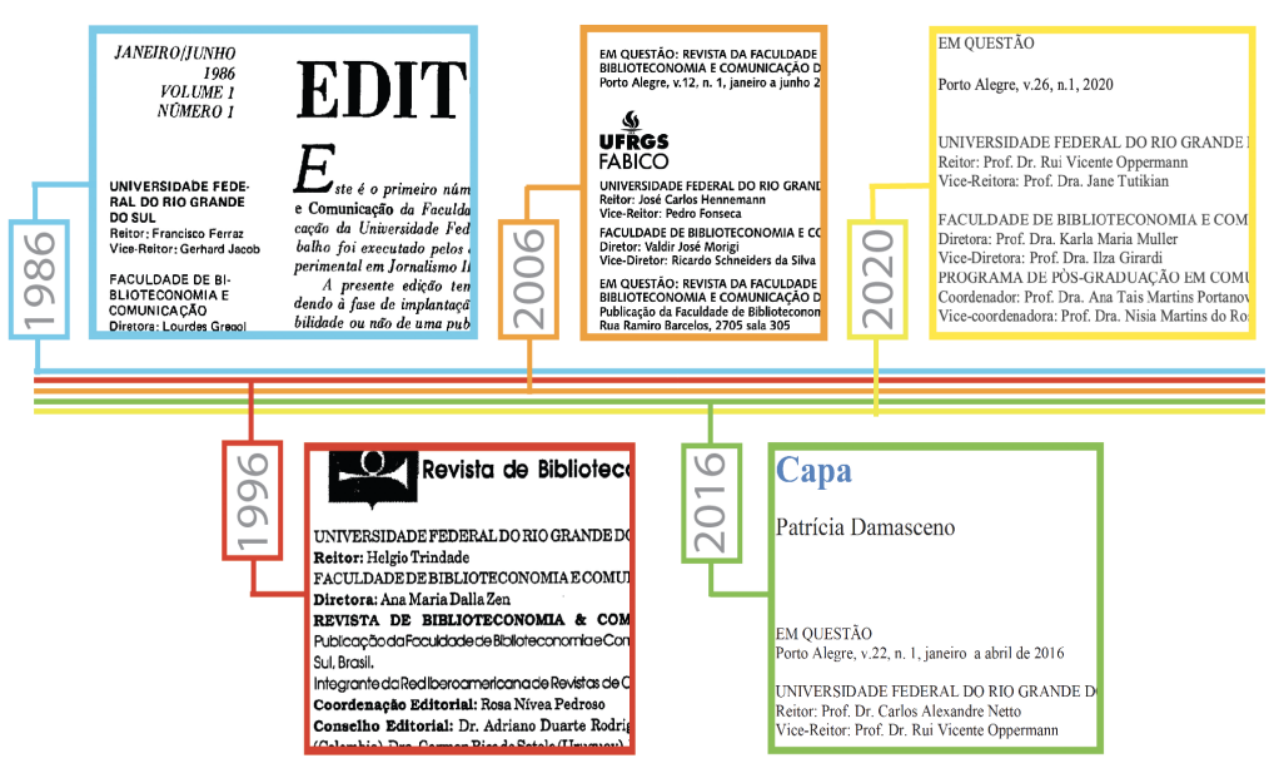

Fonte: elaborada pelas autoras (2021)

Na linha do tempo da Figura 5, pode-se observar que as páginas internas do primeiro exemplar estudado, pode-se perceber a mistura de um tipo sem serifa (nos elementos editoriais da revista) e um com serifa (no texto do editorial). Essa relação, conforme propõe Williams (2005), está corretamente estabelecida porque contrasta em estrutura. São tipos de categorias diferentes que o leitor identifica assim, não parecendo que foi um erro do diagramador, o que aconteceria se fossem empregados tipos parecidos em estrutura (como por exemplo dois tipos sem serifa). O mesmo ocorre nas páginas internas de 1996, porém neste contexto a mistura gera confusão, pois intercala no corpo do texto tipos sem e com serifa. Em 2006, excluindo-se a marca promocional da UFRGS, só aparecem tipos sem serifa. Por fim, em 2016 e 2020, apenas aparecem tipos com serifa, que segundo Passos, Passos e Vanz (2014) é a Times New Roman, que foi escolhida para o template da revista pelos critérios de leiturabilidade a disponibilidade. Entendase aqui a disponibilidade da fonte para os autores, encontrando-a instalada em seus computadores. 


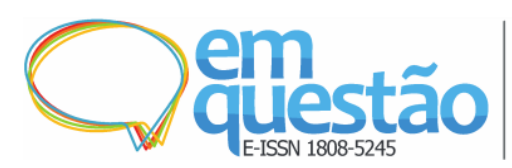

Figura 6 - Tipografia das páginas iniciais dos artigos

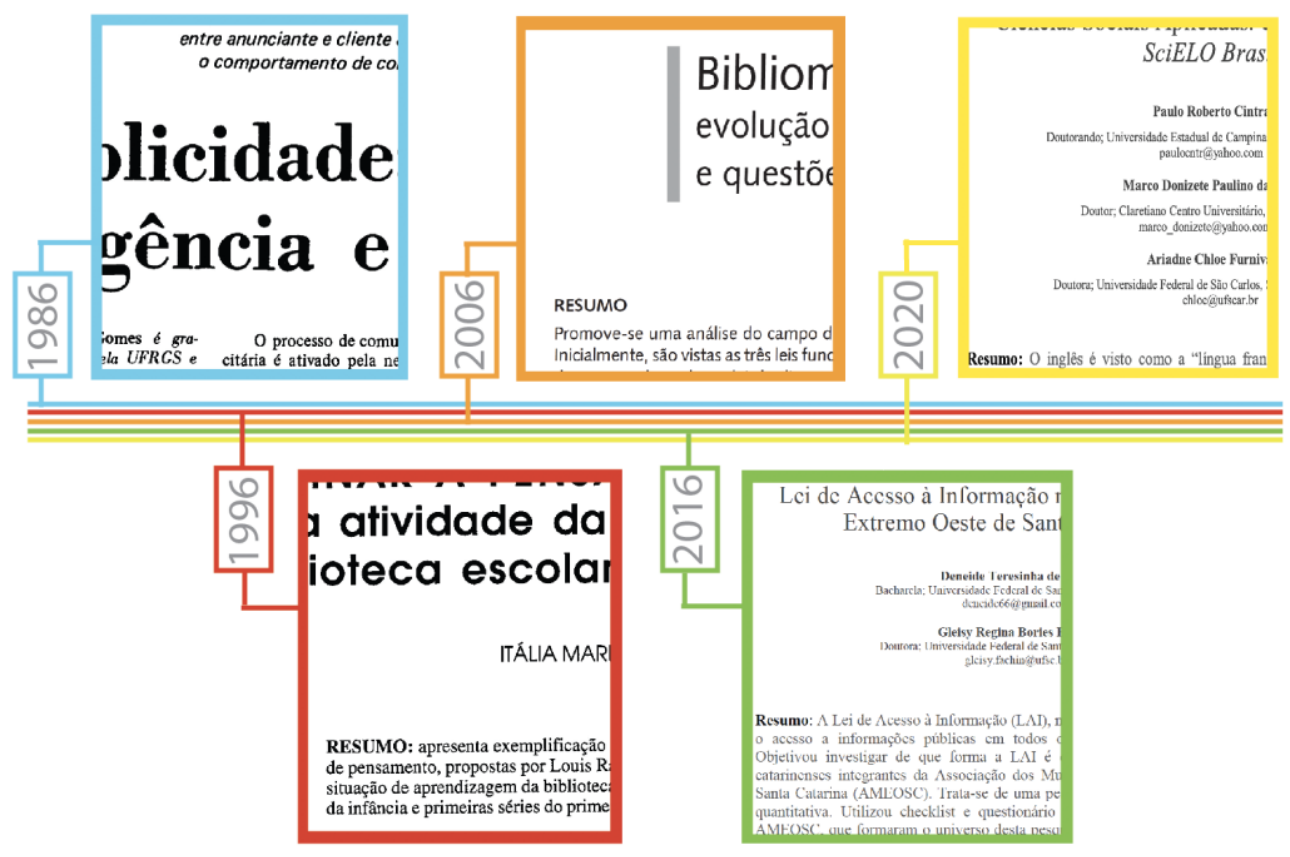

Fonte: elaborada pelas autoras (2021).

Nas páginas internas de artigos da revista (Figuras 6 e 7), tem-se, novamente, no primeiro exemplo a combinação entre tipos com e sem serifa bem configurada. O tipo sem serifa aparece somente em partes do texto que configuram divisões, como por exemplo no olho de texto, mesmo que aplicado em itálico. Na primeira página do artigo, temos um contraste bastante evidente de tamanho entre o título e o restante do texto. "Não se pode contrastar um tipo de 12 pontos com um de 14; na maioria das vezes eles simplesmente entrarão em conflito" (WILLIAMS, 2005, p. 144). Nas demais páginas de artigos, que não a primeira, existe um pequeno contraste de tamanho entre os títulos das seções do artigo e o restante do texto, mas a esse tímido contraste soma-se o contraste de peso, que acaba tornando a diferença explícita. O contraste de peso em tipografia "[...] refere-se à espessura dos traços. A maioria das famílias de tipos é desenhada com vários pesos regular, bold, às vezes semibold, extrabold ou light" (WILLIAMS, 2005, p. 148).

No segundo exemplo, nas páginas internas de artigos da revista, de 1996, foi empregada uma tipografia sem serifa apenas no título e na autoria dos artigos, 
nas demais partes do texto foi empregada uma tipografia com serifa, resultando bastante explícito o contraste tipográfico estrutural (WILLIAMS, 2005), com melhor resultado do que nas demais páginas internas, que não dos artigos, já analisadas de 1996. Entre o título do artigo e o restante do texto (Figura 6), podese verificar um contraste de tamanho bem estabelecido. Já entre os títulos das seções dos artigos e o restante do texto (Figura 7) ocorre o mesmo do primeiro exemplo: o contraste de peso adicionado ao tímido contraste de tamanho acaba funcionando para bem diferenciá-los.

Figura 7 - Tipografia das páginas demais páginas dos artigos

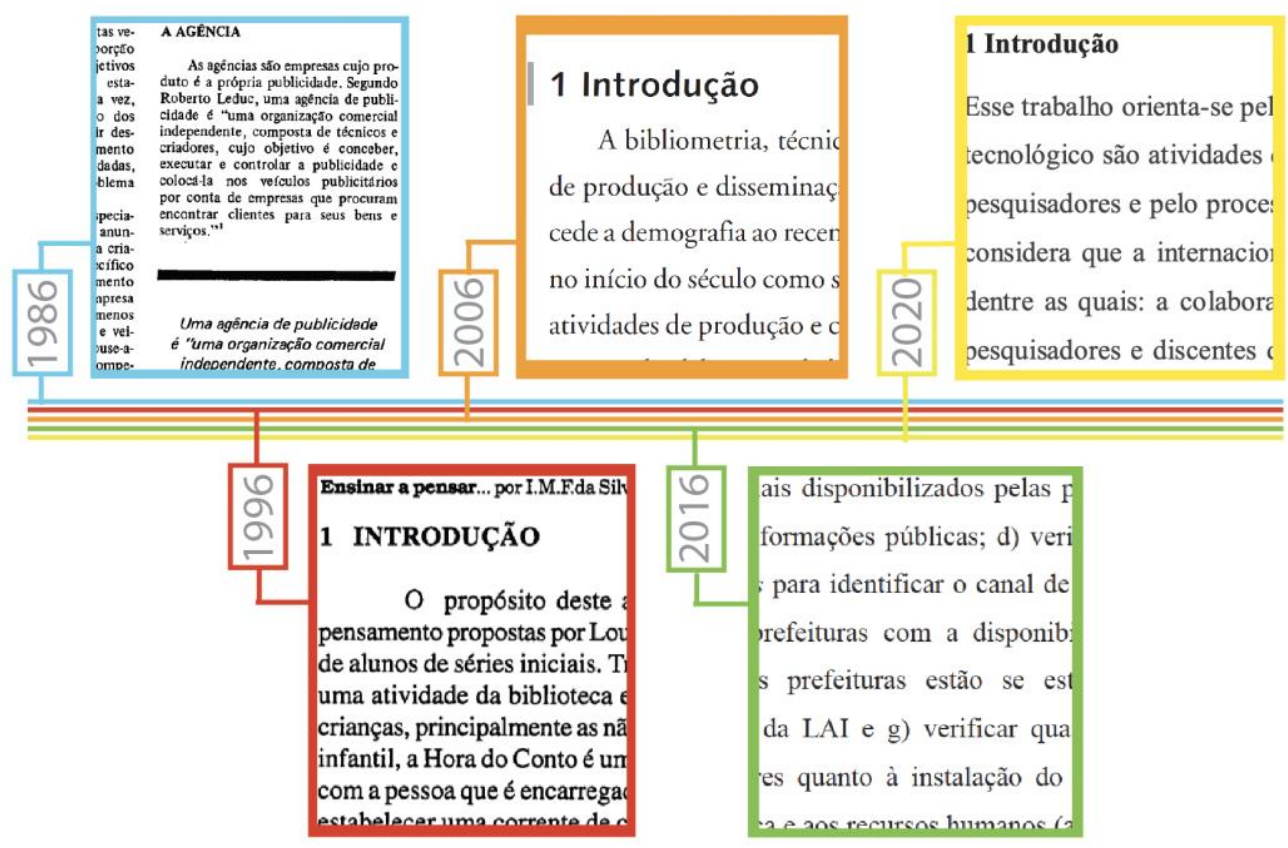

Fonte: elaborada pelas autoras (2021).

No terceiro exemplo (ano de 2006) das Figuras 6 e 7, tem-se a predominância de tipos sem serifa, porém no texto dos artigos é aplicada uma fonte classificada por Williams (2005) como de Estilo Antigo, com serifas inclinadas, transição grosso-fino moderada e leve ênfase diagonal. A fonte sem serifa é aplicada nos títulos dos artigos, nos nomes dos autores, nos títulos das seções dos artigos, no resumo e nas citações diretas. No restante do artigo, em todas as demais partes do texto, é aplicado um tipo com serifa, apresentando uma combinação claramente dividida e contrastada em estrutura. Com os demais contrastes ocorre o mesmo que com os exemplos anteriores, são contrastes de 
peso e de tamanho aplicados de forma similar, tanto entre o título do artigo e o restante do texto e os títulos das seções e o restante do texto.

Por fim, nos dois últimos exemplos de páginas internas de artigos da revista, encontra-se também apenas a Times New Roman, de acordo com o projeto de template proposto juntamente com a nova identidade visual (PASSOS; PASSOS; VANZ, 2014). Neste projeto optou-se pelos contrastes de tamanho (como exemplo corpo de texto pequeno em 8 pontos $\mathrm{X}$ corpo de texto maior em 12 pontos) e de peso (como exemplo o texto na sua forma regular X o texto em bold). Embora o contraste de tamanho siga o que recomenda Williams (2005) apenas entre o título do artigo e as demais partes do texto (onde existe uma diferença superior a 2 pontos), o conflito entre as demais partes (que seria gerado por uma diferença exata de 2 pontos e não superior como o recomendado) não chega a atrapalhar nesse contexto analisado, porque além dessa diferença no corpo do texto de 2 pontos - entre o texto e as citações diretas ou entre o texto e os títulos das figuras, por exemplo - há uma separação e uma consequente hierarquização dadas pela própria diagramação, que acaba reforçando o tímido contraste de tamanho.

\subsection{Identidade visual}

Para apresentar a análise da última categoria estabelecida na pesquisa, é preciso trazer os conceitos envolvidos em identidade visual. Strunck (2012) apresenta os quatro elementos que compõem uma identidade visual, sendo os principais o logotipo e o símbolo, os secundários as cores e o alfabeto padrão.

O logotipo "[...] é a particularização da escrita de um nome. Sempre que vemos um nome representado por um mesmo tipo de letra (especialmente criado, ou não), isso é um logotipo" (STRUNCK, 2012, p. 96). Já, segundo Neiva (2013, p. 340, grifo do autor), um logotipo consiste "[...] geralmente na estilização de uma letra ou combinação de grupo de letras com design característico, fixo e particular".

Optou-se por inserir o ano de 1990, o qual não compõe o recorte da amostra feito para as demais linhas do tempo, a fim de se evidenciar, com mais 
precisão, as alterações que ocorreram, mesmo que por vezes sutis, na evolução da identidade visual da revista.

Na Figura 8, pode-se perceber os logotipos, nos três primeiros exemplos, com a revista ainda se chamando Revista de Biblioteconomia \& Comunicação. Em nenhum dos três, encontra-se padronização, aplicando no primeiro uma combinação de fonte sem serifa com moderna, no segundo uma combinação de sem serifa com serifa grossa e no terceiro apenas fontes sem serifa. $\mathrm{O}$ primeiro e o segundo logotipos são em caixa alta e o terceiro alterna caixa alta e caixa baixa.

Figura 8 - Identidades visuais

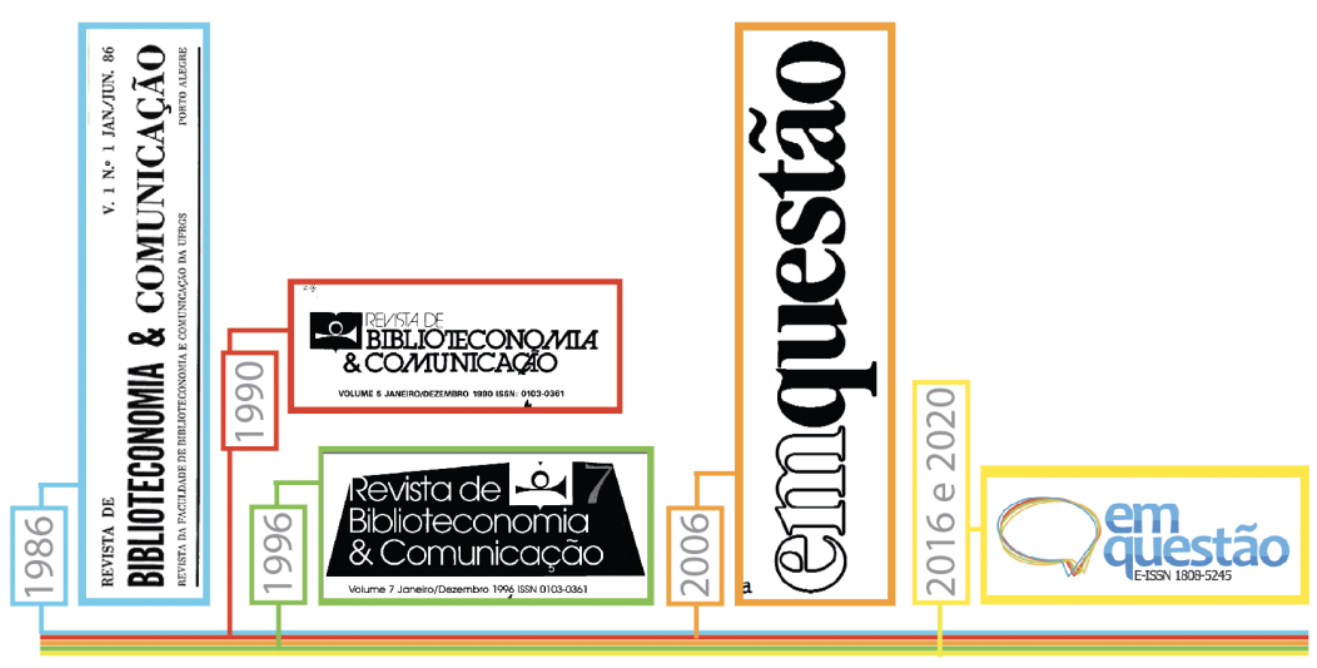

Fonte: elaborada pelas autoras (2021).

Em 2006, a revista já aparece com o novo nome, Em Questão, disposto sem separação. Aqui, o logotipo, totalmente em caixa baixa, separa o nome apresentando o "em" apenas com contorno e sem preenchimento e o "questão" apenas com preenchimento, aplicando o recurso de positivo e negativo no design.

Nos últimos dois exemplos, já com o novo projeto de identidade visual, o logotipo é diagramado em duas linhas, em tipos sem serifa, todo em caixa baixa, com preenchimento colorido e com efeito que agrega noção de volume.

Foi solicitado pela equipe editorial que se fizesse uma renovação do logotipo, e não uma revolução (quando se busca uma imagem totalmente nova). A fonte desenhada para o logotipo da revista Em Questão guarda, então, certa semelhança com o logotipo anterior, sendo sem serifa e desenhada em caixa baixa. Porém apresenta estilização, tornando o logotipo mais atual e próprio ao contexto 
digital, sua principal aplicação. A tipografia desenhada ainda possibilita boa legibilidade mesmo em reduções. (PASSOS; PASSOS; VANS, 2014, p. 15-16).

De acordo com Strunck (2012, p. 97), o símbolo

[...] é um sinal gráfico que, com o uso, passa a identificar um nome, ideia, produto ou serviço". E complementa ao afirmar que qualquer desenho pode se transformar em um símbolo,"[...] se um grupo de pessoas o entender como a representação de alguma coisa além dele mesmo.

Trata-se de uma "figura ou forma não-verbal ou predominantemente visual" (O VALOR..., 2004, p. 193), configurando na área do design gráfico um "desenho característico destinado a funcionar como elemento de identidade visual de uma empresa, organização, produto, serviço ou evento, [podendo ser abstrato ou figurativo]" (O VALOR..., 2004, p. 193).

Na Figura 8, pode-se conferir que no primeiro exemplar da revista não existia símbolo na identidade visual. Tem-se o nome da revista escrito como uma tipografia padrão, como descrito. Já no segundo exemplar, de 1987, assim como nos dois próximos de 1990 e 1996, começa a aparecer uma trompeta dentro de uma forma que remete a um balão de comunicação. Com a mudança de nome em 2003, novamente deixa de existir um símbolo na identidade visual da revista. Esse elemento volta à cena com os balões multicoloridos do novo e atual projeto de identidade visual, como mostra o último exemplo da Figura 8.

O símbolo escolhido representa a comunicação científica de forma simples e direta. A sua repetição em várias cores diferentes corresponde à multiplicidade de ideias e transmite movimento, representando o dinamismo da ciência. O azul escolhido para o logotipo representa as virtudes intelectuais. (PASSOS; PASSOS; VANZ, p. 15).

\section{Considerações finais}

Findada a análise da evolução histórica do projeto editorial da revista Em Questão, que possibilitou as inferências apresentadas, é possível apontar algumas considerações. 
A revista surgiu e evoluiu no mesmo tempo que as DTPs. Porém, até 2012, foi a versão impressa que ditou seu projeto editorial, mesmo ano em que se decidiu publicar exclusivamente a versão online. Foi quando surgiu seu novo projeto de design.

O período da revista apenas impressa e o período dela impressa mais a versão eletrônica em paralelo, estavam atrelados aos recursos disponíveis, incluindo o orçamento para sua produção gráfica, mais onerosa que a atual disponibilização digital. Portanto, mesmo depois da disseminação da editoração eletrônica, época na qual os limites técnicos praticamente não existiam mais, de mudança significativa nas ferramentas e aplicativos empregados na área do design, a revista continuava possuindo algumas limitações intrínsecas ao processo impresso. Apesar dessas limitações dadas, verificou-se um projeto editorial adequado, com diagramação profissional, texto suficientemente hierarquizado na maioria das edições, tipografia legível, contrastes tipográficos bem estabelecidos. As imagens não eram volumosas em termos numéricos, mas sua qualidade acompanhou a evolução tecnológica, exceto na questão das cores, pois a revista permaneceu em preto e branco até sua mudança em 2013. Já a capa ganhou cores, a partir de 2010, com fotografias e ilustrações de adequada resolução. Na sua nova era, a exclusivamente eletrônica, houve o incremento das cores, mas a presença de imagens ainda permanece bastante tímida, mesmo que se considere todos os tipos de imagens: gráficos, esquemas, fotografias, tabelas etc.

Já em relação à sua identidade visual, pode-se perceber que até 2003 não existia uma sistematização e padronização, o que dificultava o reconhecimento e identificação do periódico. Entre 2003 e 2012, o logotipo foi padronizado. E a partir de 2013, a revista ganhou um novo visual. A nova identidade visual, criada em 2013, procurou trazer modernidade, internacionalidade, cientificidade e atualidade como as principais qualidades, segundo os autores do projeto (PASSOS; PASSOS; VANZ, 2014).

Embora tenha havido uma evolução significativa no projeto editorial da revista, julga-se que todo o potencial do digital não esteja sendo explorado, pelo fato já citado ao longo do artigo, de ficar a cargo dos autores a diagramação dos textos a partir de um template fornecido. Ou seja, não existe uma diagramação a 
nível profissional, que se obteria a partir do uso de aplicativos também profissionais, com profissionais em diagramação executando-a. Mesmo que exista uma conceituação gráfica para a revista, como apresentado por Passos, Passos e Vanz (2014), acredita-se que exista uma limitação nos recursos visuais aplicados, imposta pela necessidade do uso de um editor de texto acessível aos autores, no caso o Microsoft Word.

Faz-se importante aqui destacar a separação entre criar o projeto gráfico de uma publicação, ligado ao ato de conceituá-lo graficamente, e diagramar o conteúdo da mesma, ligado ao ato de distribuir os textos finais nas páginas já projetadas. Deste modo, é possível projetar uma publicação, mas não diagramá-la, ou diagramar uma edição que não se projetou. (CASTEDO; GRUSZYNSKY, 2005, p. 320).

Soma-se a isso, o fato de o design gráfico não contar como critério de qualificação de periódicos científicos (ARAÚJO, 2006; CASTEDO; GRUSZYNSKY, 2005; STUMPF, 2003). Salienta-se o pensamento de Castedo e Gruszynski (2005), que chamam a atenção ao fato de que a publicação das pesquisas é bastante relevante para que não se desperdice todos os esforços feitos ao longo do trabalho. É através da publicação que os interessados terão acesso aos resultados. "A comunicação eficiente, portanto, é essencial para o processo de investigação científica" (CASTEDO; GRUSZYNSKY, 2005, p. 314). Aqui entra a preocupação com o projeto editorial, que conforme já dito, não é considerado em nenhum lugar como critério específico de avaliação, apenas citado, mas que pode interferir positiva ou negativamente na publicação da pesquisa e no reconhecimento dos autores e dos veículos.

Sendo assim, acredita-se que a comunicação entre os leitores e os autores - através dos artigos - poderia ainda ser significativamente aprimorada, utilizandose todas as vantagens que o digital oferece (em termos de cores, número de páginas, alterações de leiaute, emprego de imagens, etc.) juntamente com um trabalho profissional. Embora tenha ocorrido uma grande evolução com o novo projeto editorial da revista, ainda há potencial a ser explorado. Todos ganhariam ainda mais.

\section{Referências}


EDITORA ABRIL. A Revista no Brasil. São Paulo: Editora Abril, 2000.

ARAÚJO, Carlos Alberto. Bibliometria: evolução histórica e questões atuais. Em Questão, Porto Alegre, v. 12, n. 1, p. 11-32, jan./jun. 2006.

BRINGHURST, Robert. Elementos do estilo tipográfico. São Paulo: Cosac Naify, 2005.

CASTEDO, Raquel; GRUSZYNSKI, Ana Cláudia. A produção editorial de revistas científicas on-line: uma análise de publicações brasileiras da área da Comunicação. Em Questão, Porto Alegre, v. 17, n. 1, p. 271-287, jan./jun. 2011.

CASTEDO, Raquel; GRUSZYNSKI, Ana Cláudia. O projeto gráfico de periódicos científicos: uma contribuição aos roteiros de avaliação. Em Questão, Porto Alegre, v. 11, n. 2, p. 313-333, jul./dez. 2005.

CAUDURO, Flávio Vinicius. O design na era digital. In: MARTINS, Francisco Menezes; SILVA, Juremir Machado (org.). Para navegar no século XXI. 2. ed. Porto Alegre: Sulina/EDIPUCRS, 2000.

CAUDURO, Flávio Vinicius; FONSECA, Joaquim T. B. da. Manual de normalização. Porto Alegre: UFRGS, 1997. Disponível em:

http://www.ufrgs.br/ufrgs/noticias/arquivos/manual-de-normalizacao. Acesso em: 4 mar. 2021.

COLLARO, Antonio Celso. Projeto gráfico: teoria e prática da diagramação. São Paulo: Summus, 2000.

EM QUESTÃO. Histórico do periódico. Porto Alegre: Em Questão, [2020?]. Disponível em: http://seer.ufrgs.br/index.php/EmQuestao/about/history. Acesso em: 09 fev. 2020.

GOLIN, Cida. Apresentação. Em Questão, Porto Alegre, v. 11, n. 1, 2005.

GRUSZYNSKI, Ana Cláudia; CALZA, Marlon Uliana. Projeto gráfico: a forma de um conceito editorial. In: TAVARES, Frederico de Mello; SCHWAAB, Reges (org.). A revista e seu jornalismo. Porto Alegre: Penso, 2013. p. 203220.

HORIE, Ricardo Minoru; PEREIRA, Ricardo Pagemaker. 300 superdicas de editoração, design e artes gráficas. São Paulo: SENAC, 2001.

LUPTON, Ellen. Pensar com tipos. São Paulo: Cosac Naify, 2006.

NEIVA, Eduardo. Dicionário Houaiss de comunicação e multimídia. São Paulo: Publifolha, 2013. 
NIEMEYER, Lucy. Tipografia: uma apresentação. 4. ed. Rio de Janeiro: 2AB, 2006.

O VALOR do design: guia ADG Brasil de prática profissional do designer gráfico. 2. ed. São Paulo: Editora Senac São Paulo, 2004.

OLIVEIRA, Caroline; SANTIN, Dirce Maria; VANZ, Samile Andrea de Souza. Revista Em Questão: uma análise da sua trajetória a partir dos critérios Qualis (2003-2012). Em Questão, Porto Alegre, v. 21, n. 1, p. 8-25, jan./abr. 2015.

PASSOS, Jaire Ederson; PASSOS, Paula Caroline Schifino Jardim; VANZ, Samile Andrea de Souza. Projeto de identidade visual para a revista Em Questão. Em Questão, Porto Alegre, v. 20, n. 2, p. 8-27, jul./dez. 2014.

PEDROSO, Rosa Nívea; WEINE, Rubens Constantino Volpe. Editorial. Revista de Biblioteconomia \& Comunicação, Porto Alegre, v. 1, n. 1, p. 2, jan./jun. 1986.

PEDROSO, Rosa Nívea. Um projeto pedagógico se transforma em um projeto científico internacional: uma pequena história da Revista de Biblioteconomia \& Comunicação. Revista de Biblioteconomia \& Comunicação, Porto Alegre, v. 8, p. 291-292, jan./dez. 2000.

RABAÇA, Carlos Alberto; BARBOSA, Gustavo Guimarães. Dicionário de Comunicação. 2. ed. Rio de Janeiro: Elsevier, 2001.

ROCHA, Cláudio. Projeto tipográfico: análise e produção de fontes digitais. 2. ed. São Paulo: Edições Rosari, 2003.

SILVA, Rafael Sousa. Diagramação: o planejamento visual gráfico na comunicação impressa. 6. ed. São Paulo: Summus, 1985.

STUMPF, Ida Regina Chittó. Avaliação das revistas de Comunicação pela comunidade acadêmica da área. Em Questão, Porto Alegre, v. 9, n. 1, p. 25-38, jan./jun. 2003.

STRUNCK, Gilberto. Como criar identidades visuais para marcas de sucesso. 4. ed. Rio de Janeiro: Rio Books, 2012.

VILLAS-BOAS, André. O que é [e o que nunca foi] design gráfico. Rio de Janeiro: 2AB, 2003.

WILLIAMS, Robin. Design para quem não é designer: noções básicas de planejamento visual. 2. ed. São Paulo: Callis, 2005.

The evolution of the editorial project of the journal Em Questão 


\begin{abstract}
A historical/descriptive and subsequently interpretative research that analyzed the Editorial Project evolution of the Em Questão journal over its 35 years was developed. The textual elements (titles, body of text, citations, header, footers, captions, etc.) and imagery (cover, visual identity, figures, tables, illustrations, etc.) were first categorized, then compared and finally analyzed, generating interpretative inferences from the first edition of the magazine to the most recent ones. Among other points, it was verified that the editorial project properly evolved during the analyzed 35 years.
\end{abstract}

Keywords: Editorial Design. Em Questão. Graphic Design.

Recebido: 22/02/2021

Aceito: 01/03/2021

\title{
Declaração de autoria
}

Concepção e elaboração do estudo: Flávia Ataide Pithan e Adriana Coelho Borges Kowarick

Coleta de dados: Flávia Ataide Pithan e Adriana Coelho Borges Kowarick

Análise e discussão de dados: Flávia Ataide Pithan e Adriana Coelho Borges Kowarick

Redação e revisão do manuscrito: Flávia Ataide Pithan e Adriana Coelho Borges Kowarick

\section{Como citar}

PITHAN, Flávia Ataide Pithan; KOWARICK, Adriana Coelho Borges. A evolução do projeto editorial da revista Em questão. Em Questão, Porto Alegre, v. 27, n. 2, p. 26-51, abr./jun. 2021.

\footnotetext{
${ }^{1}$ MEADOWS, A. J. A. Comunicação científica. Brasília: Briquet de Lemos, 1999. Apud Passos, Passos e Vanz (2014).

${ }^{2}$ GARRETT, J. J. The elements of user experience: user centered design for the web. New York: Aiga; Berkeley: New Riders, 2003. Apud Passos, Passos e Vanz (2014).
} 